anaemia, various unrelated painful conditions of the lower limbs, chronic pulmonary diseases (Dr. Spillane's cases), uraemia, gastric surgery, and diabetes mellitus. ${ }^{4}$

The following case illustrates the adverse influence of pregnancy. During the later stages of each of her four pregnancies this patient experienced frequently recurring "heavy ache" in the limbs, followed by "spontaneous jerking." The affection involved all four limbs and rendered sleep virtually impossible. When seen some ten years later she reported that she had remained free from these symptoms. These are intensifying influences rather than precipitating factors, since an inquiry will often reveal past episodes of "dyslysis" of mino degree of severity. There may well be an element common to all these divers inf'uences. The disorder can also be "acquired" in multiple sclerosis and Parkinsonism. Anaemia is perhaps the most powerful intensifying factor. Because correction of anaemia - for example, in menorrhagia-will often relieve "dyslysis" completely, it should always be borne in mind in the management of these cases. Reference must also be made to the absence of seizure patterns in the electroencephalogram concurrent with "nocturnal" myoclonus, yet there is little doubt that anticonvulsants, including diazepam, are effective in the treatment of this complaint, which, as Dr. Spillane says, can be of "tormenting nature."-I am, etc.,

London $\mathbf{W} .1$

SIMON BEHRMAN

1 Behrman, S., British Medical fournal, 1958, 1, 2 Willis, $T$

illis, T., Quoted by Banerii, N. K., and Hur-
witz, L. J., British Medical Ұournal, 1970, 4, Callaghan, N., Neurology (Minneapolis), 1966, 16, Banerii, N. K., and Hurwitz, L. J. British Medical
fournal, 1970, 4, 774.

\section{Medical Management of}

Rheumatoid Arthritis

SIR,-Dr. R. Bluestone's article on the medical management of rheumatoid arthritis (5 December, p. 602) prompts us to take issue with him on several points. We feel well qualified to offer an alternative view because we spend a good deal of time trying to salvage something from the wreckage of joints which orthodox laissezfaire treatment too often leaves behind.

It is futile to treat severe progressive disease with weak, so-called anti-inflammatory agents, which in effect are glorified analgesics. We believe it is wrong to follow the usual sequential method in such cases, since by the time the physician has applied various drugs in turn and found them inadequate irreparable damage has been done to the joints. All too often the space of 18 months witnesses the change from normality to crippling. Perhaps $10 \%$ of patients with seropositive arthritis are in this category. The time is short; their urgent need is for treatment which will be effective with the least possible delay. Aspirin in full dosage, phenylbutazone, indomethacin, and other analgesics are worse than useless in this situation; they ensure only a more comfortable ride to destruction. Only steroids can influence the disease quickly enough to affect the outcome, and the early addition of immunosuppressives may often be advisable.

The use of intra-articular injections of steroids into weight-bearing joints in ambulant patients is often unhelpful if the disease in general is active, and it may increase the risk of joint damage by removing the protection of pain. To describe this as the mose useful role of steroids in rheumatoid disease is short sighted.

The side effects of corticosteroid treatment in small to moderate dosage are less to be feared than the side effects of unrestrained disease; except for pituitary-adrenal inhibition most can be controlled by strict attention to various simple, if tedious, precautions. The toxic effects of chloroquine are less frequently disastrous than $\mathrm{Dr}$ Bluestone thinks, provided that the dosage is moderate and the treatment intermittent. There is evidence that retinal damage may be prevented by protection from ultraviolet light (a minor problem in this country) Moreover, the published reports of controlled trials have not advocated high-dose chloroquine therapy. We agree that gold is often useful and effective, but Dr. Bluestone should remember the limitations as well as the advantages of chrysotherapy; these were clearly defined in the report on the Empire Rheumatism Council trial, ${ }^{1}$ which showed that, in common with antimalarials, gold (under the conditions of the trial) did not influence progression of erosions seen radiologically.

It is crucial that patients should be stratified according to their individual prognosis at an early stage and that appropriate treatment should be given without waiting for gross joint destruction to become evident. It is also desirable that the policy for each patient should be reviewed at regular intervals and that a policy which is failing should be changed.-We are, etc.,

A. J. POPERT B. L. Coulton Highfield Hospital, roitwich, Worcs Empire Rheumatism Council Annals of the
Rheumatic Diseases, 1961, 20, 315.

\section{Selective Vagotomy without Drainage}

SIR,-Fifteen months ago I reported the early results of bilateral selective vagotomy without drainage (20 September, 1969, p. 690 ). The omission of any drainage operation was based on the hypothesis that if truncal vagotomy made a drainage operation obligatory bilateral selective vagotomy, by preserving innervation of the pylorus and duodenal bulb, might allow good gastric emptying without any drainage procedure.

A special food-barium meal was used to study gastric emptying, a film being taken at nine hours and the degree of retention expressed by the size of the barium residue as $0,+,++$ and +++ (see 1969 paper). When the special meal was given to 15 "normal" people 13 were graded 0 and two graded + . The results obtained in 1969 in 17 patients after vagotomy and a single layer Heineke-Mikulicz pyloroplasty are shown in Table I.

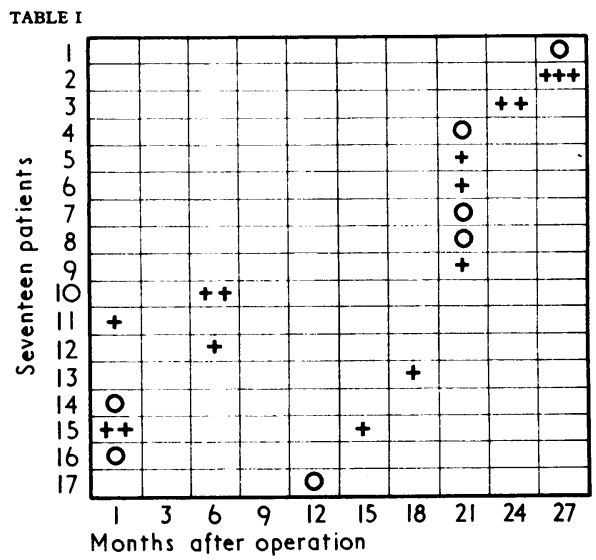

Twenty unselected patients have now been examined one year after bilateral selective vagotomy without drainage. Care was taken to exclude any patients for this operation in whom any degree of organic duodenal narrowing was present. The results (Table II) show that one year after bilateral selective vagotomy without drainage in patients with duodenal ulceration but without organic stenosis gastric emptying is virtually normal. Indeed the stomach empties better without drainage than it does with pyloroplasty. The drainage operation should wherever possible be omitted for there is wide agreement that most of the sequelae of selective vagotomy and drainage are due to the pyloroplasty or gastro-jejunostomy and not to the vagotomy itself.

Some 120 patients have now been treated in this way since April 1967. Not one case has developed lesser curve gastric ulceration. Our studies suggest that when selective vagotomy is used without drainage care must be taken to exclude organic narrowing for mucosal stenosis may be more severe than the muscular narrowing of the duodenum suggests. In some cases the duodenum must be dissected free from adhesions before the muscular narrowing can be seen.

The pyloric branches of the hepatic plexus supply, as Latarjet showed, the pylorus and the duodenal bulb and probably too a very small amount of prepyloric stomach. He stated that the nerves, which we now know by his name, do not reach the pylorus and this fact can be clearly demonstrated in man at operation. Presumably, therefore, the immediate prepyloric stomach is supplied by the pyloric branches from the hepatic plexus. These pyloric branches may be easily stimulated in man. Care must be taken to see that no anti-cholinergic drugs have been previously given. The pylorus and duodenal bulb are seen to contract when the stimulus is applied. If a clamp is placed across the duodenum beyond the bulb, the motor function of these pyloric branches may be demonstrated by a rise in intragastric pressure on stimulation. It seems that bilateral selective vagotomy without drainage is an important step in the evolution of vagotomy. It should encourage us to operate before organic narrowing has occurred.

We now await with interest the late results of highly selective vagotomy without drainage. ${ }^{1-3}$ This important modification is yet another step forward in vagotomy. Already we may claim almost without doubt that highly selective vagotomy without drainage is not followed by recurrent duodenal ulceration nor by gastric ulceration 